\title{
Letter from the Editor-in-Chief
}

\author{
Peter G. M. de Jong ${ }^{1}$
}

Published online: 30 October 2018

(C) International Association of Medical Science Educators 2018

Welcome to the fourth issue of Medical Science Educator of 2018. This issue features 33 new manuscripts reporting on medical education, which I hope will be of interest to you. It also contains a special section on "Nutrition Education." Several of our readers responded to the call of the Editorial Board to submit manuscripts on this topic. For my introduction to the theme, please read further in this issue.

After years of dedicated service to our journal, Associate Editor Wayne Lambert (USA) recently stepped down from the Editorial Board due to new commitments and responsibilities at his school. Wayne has been a loyal member of the Editorial Board and has spent a considerable amount of time meticulously reviewing manuscripts and working with the authors on revisions. The Editorial Board appreciates his efforts, collegiality, and friendship over all these years and we wish him all the best for the future.

The Board is happy to see that every year more and more educators find their way to Medical Science Educator to present their scholarly work. I therefore hope you will enjoy this issue and that you will continue supporting Medical Science Educator both as a reader and as an author of your own scholarly work for the benefit of our work and the work of others!

Peter G.M. de Jong, PhD

Editor-in-Chief

Peter G. M. de Jong

P.G.M.de_Jong@lumc.nl

1 Leiden University Medical Center, Leiden, The Netherlands 